Ventilation effects on the thermal characteristics of fire spread modes in open-plan compartment fires

Vinny Gupta ${ }^{a^{*}}$, Juan P. Hidalgo ${ }^{a}$, Adam Cowlard ${ }^{b}$, Cecilia Abecassis-Empis ${ }^{\mathrm{b}}$, Agustin H.

4 Majdalani $^{\mathrm{c}}$, Cristian Maluk ${ }^{\mathrm{a}}$, Jose L. Torero ${ }^{\mathrm{d}}$,

5 aSchool of Civil Engineering, The University of Queensland, Brisbane, Australia,

6 v.gupta@uq.edu.au, j.hidalgo@uq.edu.au, c.maluk@uq.edu.au

7 b TAEC Ltd., 51/4 Salisbury Road, EH16 5AA, Edinburgh, United Kingdom,

8 adam@taec.engineering, cecilia@taec.engineering

${ }^{\mathrm{c}}$ MB Nexus Ltd., 6 St. Colme Street, EH3 6AD, Edinburgh, United Kingdom, ahmajdalani@gmail.com

${ }^{\mathrm{d} D e p a r t m e n t ~ o f ~ C i v i l, ~ E n v i r o n m e n t a l ~ \& ~ G e o m a t i c ~ E n g i n e e r i n g, ~ U n i v e r s i t y ~ C o l l e g e ~ L o n d o n, ~}$ London, United Kingdom, j.torero@ucl.ac.uk

$13 *$ Corresponding author

\title{
14 Abstract:
}

Our understanding of fire behaviour and heating conditions for load-bearing structural elements was developed from an immense body of research in small under-ventilated compartment fires. Within the context of contemporary architecture, large open-plan compartments are commonplace, yet understanding of the first principles that define fire behaviour in such enclosures remains limited. Past experiments have revealed that fires in open-plan compartments exhibit three distinct fire spread modes: a fully-developed fire, a growing fire, and a travelling fire. This paper studies the thermal characteristics arising from these fire spread modes and the effects of the ventilation imposed. An experimental analysis of the energy distribution and spatial heating is conducted on a series of large-scale compartment fire tests, with the fire spread mode and ventilation conditions systematically varied. Each fire spread mode is shown to induce significant and characteristic spatial heat distributions. Moreover, the analysis of the ventilation modes shows equivalent thermal loads imposed on the structure in cases where the opening areas are large, and plume flows are dominant despite lower gas temperatures and irradiation. Thus, fires in open-plan compartments pose unique and possibly more severe thermal loading to structural systems, a characteristic not captured by current design fire methodologies.

Keywords: Compartment fires, Fire dynamics, Heat transfer, Large-scale experiments, Structural fire design, Tall buildings, Compartment fire framework, Travelling fires

\section{Introduction}

The built-environment has experienced rapid development in the past few decades, with a key focus on coupling the need for new materials, architectural innovation, greater energy efficiencies, space optimisation, and cost optimisation. When balancing these elements against fire safety considerations, adequate characterisation of the fire dynamics beyond the early growth stage of the fire is required. Structural fire designs have traditionally been based on the assumption of temperature homogeneity such that the design fire can be described using a single temperature-time evolution established by methodologies such as the Compartment Fire 
Framework [1]. Such methodologies are intended to provide practitioners with a conservative quantification of thermal conditions for fully-developed fires in small cubic compartments $(<150$ $\mathrm{m}^{3}$ ). The bounds of limitations for these design fires is established in the literature [2]. However, their application is in direct contradiction with the evolution of the built environment, for which the geometry of the compartment departs from a small cube and towards large open-plan and well-ventilated spaces [3]. This transition has been shown to be complex, with the thermal characteristics of the compartment changing from one of homogeneity to one of heterogeneity [4]. Furthermore, disasters such as the World Trade Centre towers [5] and experiments such as those conducted at Cardington [6] have revealed that fires in large, open-plan compartments may not occupy the entire floor plate, but instead can spread or travel along the floor plate, resulting in the structure being exposed to spatial temperature distributions.

Based on these observations, three characteristic fire spread modes: (1) a fully-developed fire, (2) a steady-growing fire, (3) a travelling fire, were hypothesised and studied in the Real Fires for the Safe Design of Tall Buildings Project [7]. These modes are differentiated by their characteristic relationship between the spread velocity of the fire front and the spread velocity of the burnout front. These fire spread modes were experimentally demonstrated in the Malveira Fire Test [8], producing different levels of characteristic thermal behaviour for each mode. It was postulated that each fire spread mode and the transitions between the modes are determined by the spatial distribution of energy in the compartment. At small scales, ventilation is accepted as the most critical parameter that drives the thermal characteristics of a compartment fire [9]. However, the relationship between ventilation and the thermal characteristics of fully-developed and transient fires in larger compartments is not well understood. This work aims to study the effects of ventilation on the energy distribution and spatial heating of the different fire spread modes in an open-plan compartment.

\section{Edinburgh Tall Building Fire Tests (ETFT)}

A detailed description of the experimental compartment and the campaign of experiments is presented by Hidalgo et al. [7]. The internal dimensions were $17,800 \mathrm{~mm}$ x $4,900 \mathrm{~mm} \times 2,000$ $\mathrm{mm}$, shown on Fig. 1a. The dimensions of the compartment were selected to represent a scaleddown version of an open floor plan compartment typical in an office building. One side of the compartment was fully open with a $500 \mathrm{~mm}$ overhang, and fitted with a shutter system to control 15 independent segments of the opening, such that the opening factor is varied (refer to Fig. 1b). Each shutter measured 1,400 $\mathrm{mm}$ wide x $2000 \mathrm{~mm}$ high, and consisted of a steel frame, supported with mineral wool insulation, and mounted on a guide rail with wheels, shown on Fig. 1c. The shutters did not close the opening tightly, thus providing a gap at the top rail.

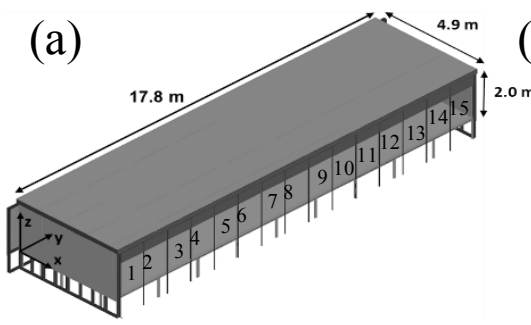

(b)

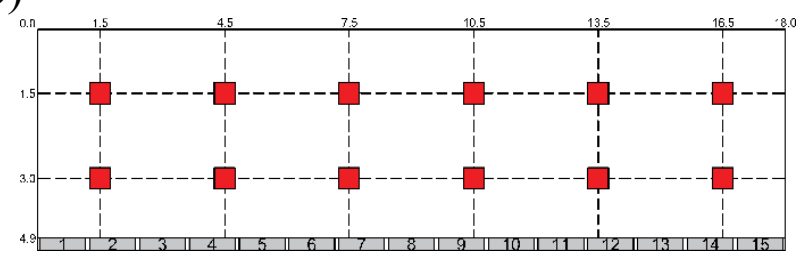

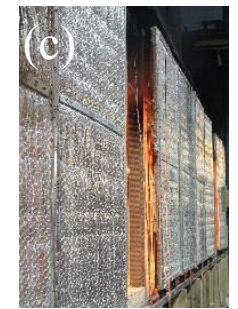

Fig. 1. (a) Isometric sketch of the experimental compartment geometry, with internal dimensions.

(b) Plan view of the burners and opening shutters. (c) Shutters system covering the openings. 
Key instruments used in this study include over 1,800 Type K thermocouples (1.5mm bead), 274 thin-skin calorimeters (TSCs) [10], 30 bi-directional probes [11], 5 gas analyser probes $\left(\mathrm{O}_{2}, \mathrm{CO}_{2}\right.$ and $\mathrm{CO}$ ), and 12 custom-built sand gas burners. The purpose of each measurement and the spatial arrangements of the sensors are described by Maluk et al. [12] and Gupta et al. [13].

\subsection{Fire Spread Modes}

When considering the fire development in large compartments; significant variations in the fire spread modes are expected, influencing the thermal environment. Three fire spread modes are studied based on the relationship between the fire front spread velocity ( $(k)$ and burnout spread velocity $\left(V_{B O}\right)[7]$. The spread modes are controlled using the propane gas burners to simulate:

1. a fully-developed fire where $k / V_{B O} \rightarrow \infty$ (representative of a post-flashover fire)

2. a growing fire where $\measuredangle / V_{B O}>1$ (representative of a growing pre-flashover fire)

3. a travelling fire where $\measuredangle / V_{B O} \approx 1$ (no flashover, spread and burnout rate are constant)

\subsection{Ventilation Modes}

Within the bounds of applicability of the traditional compartment fire framework, the historical description of the ventilation-controlled and fuel-controlled fires regimes are given by Thomas [9]. These regimes are limiting cases of post-flashover fires in compartments and are obtained due to the ventilation effects on the flow behaviour [1]. The ventilation mode is defined as the principal mechanism of flow within, into and out of the compartment [14], and is determined by the available ventilation, expressed through the inverse opening factor:

$$
\phi^{\prime}=A_{\uparrow} / A_{0} \sqrt{ } H_{0}
$$

where $A_{T}$ is the surface area of the compartment minus the fuel $(\mathrm{m}), A_{0}$ is the area of the openings $\left(\mathrm{m}^{2}\right)$, and $H_{0}$ is the height of the openings $(\mathrm{m})$. The effects of the ventilation mode on the thermal environment is explored by bounding the inverse opening factor at two extremes:

1. Unrestricted openings, $\phi^{\prime} \approx 4 m^{-0.5}$ (all fifteen opening segments left open)

2. Restricted openings, $\phi^{\prime} \approx 23 m^{-0.5}$ (segments 3,8 , and 13 in Fig. 1a are left open)

\section{Energy distribution analysis}

The small cubic compartment fire experiments underpinning the compartment fire framework [15] demonstrate the relationship of ventilation to the distribution of energy, and by extension, the thermal characteristics of the compartment. Within the context of open-plan compartments, the link between the ventilation mode and the distribution of energy remains unknown. To this purpose, the high density of sensors within the compartment is exploited to quantify the rates of energy transfer within and out of the compartment, thus enabling a discrete temporal and spatial analysis of the energy distribution. Therefore, a comparison of the thermal characteristics under two ventilation modes is made. Treating the compartment as a control volume, the energy conservation equation is

$$
\left(d Q_{c v}\right) / d t=Q_{\text {fire }}+Q_{\text {in, ent halpy }}-Q_{\text {out,enthalpy }}-Q_{\text {out, radiation }}-Q_{\text {solid }}
$$

where $d Q_{c v} / d t$ is the transient energy term, $\dot{Q}_{\text {frie }}$ is the input heat from the gas burners, $\dot{Q}_{\text {in,enthalpy }}$ and $\dot{Q}_{\text {out,enthalpy }}$ are the enthalpy of the cold inflow gases and hot outflow gases 
through the openings respectively, $\dot{Q}_{\text {out }, \text { radiaiton }}$ is the radiative heat losses through the openings, and $\dot{Q}_{\text {solid }}$ is the conduction losses through the walls of the compartment. Quantification of the terms in Eq. 2 was attempted for these experiments by Maluk et al. [12]. The key assumptions made were that radiation was considered negligible [15] and that the flow profile at the openings is linear. The simple representation of the flow profile was attributed to limited bi-directional gas flow probes positioned at each opening. Maluk et al. [12] found that the energy calculated using the instruments in the compartment could not account for the energy generated by the combustion. Therefore, a robust assessment of the thermal environment was not possible. They conclude that the approach must be refined. On this basis, the following elements are evaluated:

1. The flow profile at the opening, which influences the amount of energy lost through the openings. The flow profile shall be re-evaluated considering the temperature profile at the openings, errors in the bi-directional probes and pressure transducers, and the radiation error in the gas-phase thermocouples.

2. Radiation losses through the openings, which affect the energy lost through the opening.

3. Convective heat transfer, which influences the net heat transfer to the solid boundaries.

The approach to calculating the heat loss terms described herein assumes that the temperatures measured correspond to the gas-phase temperatures. Temperatures are corrected using the method described by Welch et al. [16]. Average corrections are low, ranging $\pm 25^{\circ} \mathrm{C}$ for all thermocouples within the compartment irrespective of ventilation condition and fire mode, likely due to the low soot volume fractions. By using the video footage and flow data, the uncertainty is eliminated by setting gas-phase temperatures below the neutral plane to ambient temperatures.

\subsection{Flow profile at the opening}

Evaluation of the flow errors in the bi-directional probes and pressure transducers for these experiments were evaluated by Gupta et al. [13]. The net enthalpy exchange at the opening is

$$
Q_{\text {out }, \text { enthalpy }}-Q_{\text {in,ent halpy }}=\dot{m}_{\text {out }} f_{, \infty}\left(T_{H}-T_{\infty}\right)
$$

where $\dot{m}_{\text {out }}$ is the mass flow rate of the hot gases leaving the compartment, $c_{p, \infty}$ is the specific heat capacity of air at ambient conditions, $T_{H}$ is the average hot layer temperature. The methodology for calculating $\dot{m}_{\text {out }}$ and $T_{H}$ using the experimental data is detailed by Gupta et al. [13] and implemented in this study.

\subsection{Radiation exchange at the opening}

Given the large openings in the experimental compartment, the assumption of negligible radiant heat loss term for small openings as in [12][15] is challenged by evaluating the upper-bound of this term. The radiation loss term is given as:

$$
\dot{Q}_{\text {out, }, \text { adiation }}=\sum F_{l \rightarrow 0} E A_{i}
$$

where $F_{i \rightarrow o}$ is the view factor of the radiating element to the opening (-), $E_{i}$ is the emissive power of each radiating element $\left(\mathrm{kW} \cdot \mathrm{m}^{-2}\right)$; calculated by $E=\varepsilon_{i} \sigma T_{i}^{4}$, and $A_{i}$ is the surface area of each radiating element $(\mathrm{m})$. To calculate the upper-bound of radiation losses, a simple model is constructed by assuming the following: 
1. Smoke layer and thermal interface heights are approximately equal $\left(H_{s} \approx H_{l}\right)$

2. Opaque smoke layer $(\tau=0)$

\section{Non-participating atmosphere under the smoke layer}

4. A constant, effective flame temperature $\left(T_{F}\right)$

The smoke layer and spill plume are treated as a solid black body, discretised by each of the fifteen openings. The smoke layer is assumed in be uniform in depth. Flames emanating from each burner are modelled as a rectangular prism, decomposed into five faces. Each face of the flame is modelled as a solid radiating surface. The radiating area of each flame is determined by assuming the width of the flame to be equal to the burner width, and the flame height is calculated using Heskestad's correlation [17]. Any portion of the flame that is immersed in the smoke layer is attenuated and not considered in calculating the area of the flame.

The effective flame temperature and the flame emissivity for a propane gas burner is defined from the literature [18]. Given the assumption that a uniform flame temperature is not accurate, a higher and lower bound of effective flame temperatures range from $1100 \mathrm{~K}$ to $1400 \mathrm{~K}$. The smoke layer and spill plumes are treated as black bodies; thus, the emissivity is unity, $\varepsilon_{i}=1$. The view factor for the spill plume is assumed to be unity $\left(F_{i \rightarrow 0}=1\right)$. View factors for each radiating surface to the openings are solved numerically using Stokes' theorem.
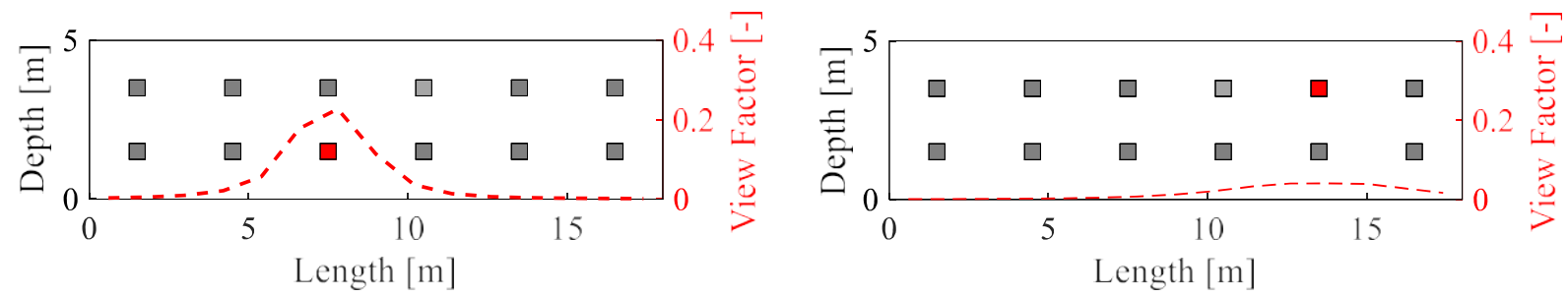

Fig. 2. Cumulative view factor distribution of the highlighted flames

The spatial distribution of the cumulative view factor of a burner (highlighted in red) located towards the front and rear of the compartment is shown in Fig. 2. For burners close to the openings, the view factors local to the burner peaks at 0.21 . Towards the rear of the compartment, view factors peak at 0.05 .

\subsection{Convective heat transfer coefficients}

Consideration of the convective heat transfer coefficient is necessary to capture the heat transfer to the solid boundaries. No flow data was captured inside the compartment; therefore, the evaluation of the quantification of flows is based on past numerical work by Gupta et al. [13]. Due to the large spatial distribution in velocities, a range of convective heat transfer coefficients are defined. This is achieved by bounding the maximum and minimum characteristic velocities along the boundaries in the model; $v_{c}=2.25 \mathrm{~ms}^{-1}$ and $v_{c}=0.50 \mathrm{~ms}^{-1}$, respectively. The convective heat transfer coefficient is assumed to be a function of the Reynolds number and is turbulent. The Nusselt number is evaluated empirically as a turbulent forced flow over a flat plate [19].

$$
N u=L_{c} h_{c} / k_{\text {gas }}(T)=0.037 \operatorname{Re}^{4 / 5} \operatorname{Pr} 1 / 3
$$

where $L_{c}$ is the characteristic length of the boundary element (ceiling and walls) and is assumed to be $1 \mathrm{~m}, k_{\text {gas }}$ is the thermal conductivity of the gas, $R e$ is the Reynolds number and $\operatorname{Pr}$ is the Prandtl number. The convective heat transfer coefficient $\left(h_{c}\right)$ ranges from 2.0 to $8.3 \mathrm{~W} \cdot \mathrm{m}^{-2} \mathrm{~K}^{-1}$. 


\section{Experimental Results}

188

189

190

191

192

193

194

195

196

197

198

199

200

201

202

203

204

205

206

207

208

209

210

211

212

213

214

215

216

217

218

219

The energy equation (Eq. 2) is solved for the fire spread modes under the two ventilation modes. The unsteady term $\left(d Q_{c v} / d t\right)$ is neglected from the analysis as this term is generally negligible due to the low volumetric heat capacity of air [12] and the simulated fire modes are mostly steady-state [12]. The solid-phase heat transfer is calculated using a similar numerical methodology described by Maluk et al. [12], with the exception being the calculation of the convective heat transfer coefficient. The summation of the loss terms $\left(Q_{\text {out ent } h a l p y}, \hat{Q}_{\text {out, radidition }}\right.$, $\left.\dot{Q}_{\text {solid }}\right)$ calculated using the approach proposed is represented by $\dot{Q}_{\text {loss }} ;$ the total heat loss term. The heat release rate (HRR) of the fire for each experiment is shown as $\dot{Q}_{\text {fire }}$.

\subsection{Unrestricted ventilation mode}

The HRR of each fire spread mode experiment in unrestricted ventilation mode $\left(\phi^{\prime} \approx 4 m^{-0.5}\right)$ is shown in Fig. 3a. The total heat losses for each fire spread mode are normalised by the HRR.
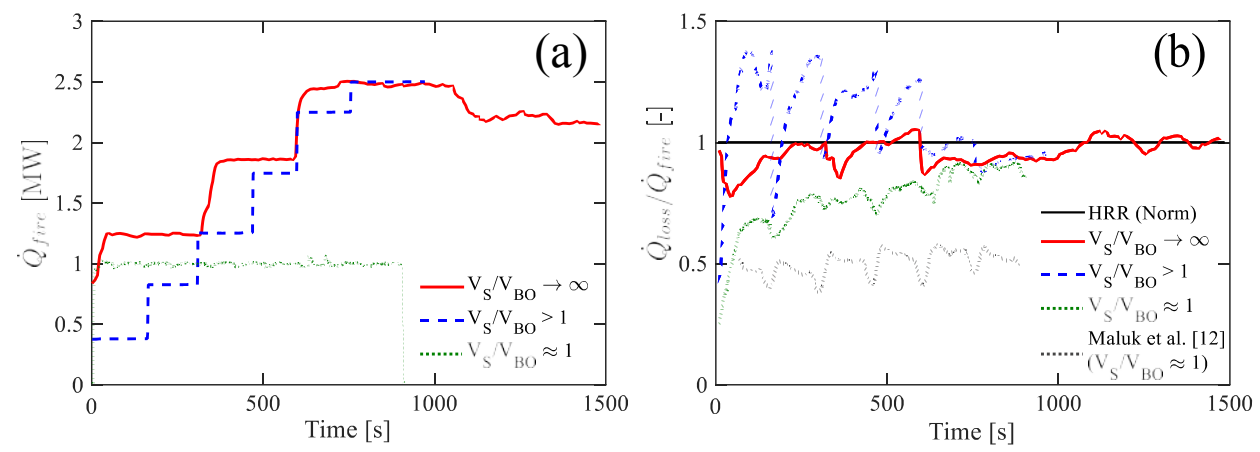

Fig. 3 Energy conservation terms for the high ventilation regime (a)HRR $\left(\dot{Q}_{\text {fire }}\right)$ generated by the burners for three fire spread modes. (b) $\dot{Q}_{\text {loss }}$ normalised by $\dot{Q}_{\text {fire }}$ for each fire spread mode.

The total heat loss for each fire spread mode in Fig. 3 b corresponds closely to the HRR. The result of $Q_{\text {lass }}$ for the travelling fire experiment $\left(\bigvee / V_{B O} \approx 1\right)$ is compared to results by Maluk et al. [12], with noticeable improvements in the calculation of the heat loss terms observed. This trend is mirrored in the evaluation of the total heat losses for each fire spread mode. Transient variations in the total energy loss term correspond to changes in the heat supplied by the burners. The total heat loss stabilises once the HRR is steady, with a delay in the travelling fire mode noted as the smoke layer is not well-established. Thus some of the flow is not captured by the bidirectional probes. Average hot layer temperatures range from $230^{\circ} \mathrm{C}$ to $265^{\circ} \mathrm{C}$, inflow velocities range from $0.4 \mathrm{~m} . \mathrm{s}^{-1}$ to $0.6 \mathrm{~m} . \mathrm{s}^{-1}$, and outflow velocities range from $0.8 \mathrm{~m} \cdot \mathrm{s}^{-1}$ to $1.05 \mathrm{~m} . \mathrm{s}^{-1}$.

Fig. 4a shows the breakdown of the energy loss terms for the high ventilation experiments averaged over a steady-state period at the peak HRR. Majority of the heat (75\% to $80 \%)$ is lost through convection at the openings. The large error bars for the convective heat losses illustrate the significant spatial variations in the thermal interface height and hot layer temperatures in this ventilation mode. Once again, the largest error bars for the convective losses are noted for the travelling fire spread mode $\left(\mathrm{V} / V_{b 0} \approx 1\right)$. Radiation losses through the openings are shown to be high for the fully-developed and growing fire spread modes, ranging from $6 \%$ to $10 \%$ of the HRR. This range is sensitive to the effective flame temperature, as shown in the error bars. Heat losses to the boundaries are very low, $6 \%$ to $8 \%$ of the input HRR. Due to the small solid-phase 
losses, the effects of the convective heat transfer coefficient are negligible, hence the error bars are small. Breaking down the solid-phase heat losses per element in Fig. $4 \mathrm{~b}$ reveals that the most heat losses are to the back wall and ceiling, with losses to the back wall generally being slightly higher. Gas-phase temperatures and irradiation towards the back wall and ceiling are higher also, similarly noted by Majdalani et al. [4].
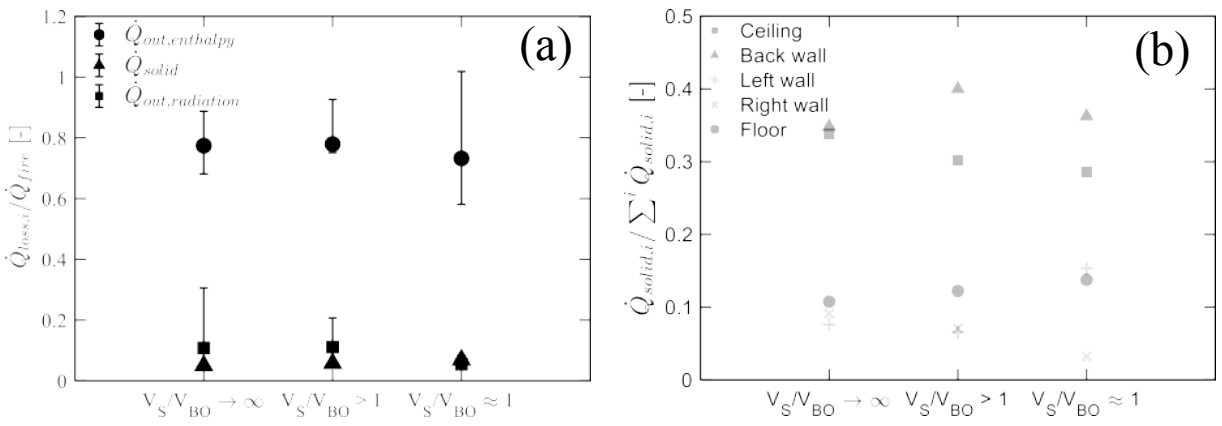

Fig. 4. Distribution of energy for the unrestricted ventilation mode. (a) Breakdown of the heat lost outside of the control volume to convection, radiation, and conduction. (b) Breakdown of the conduction losses to the various boundary elements in the compartment.

\subsection{Restricted ventilation mode}
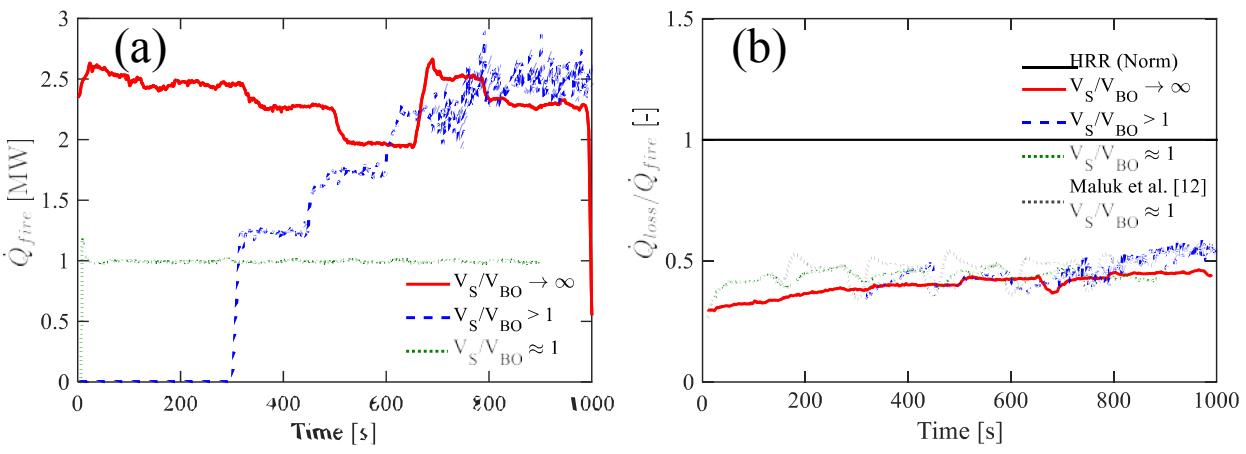

Fig. 5. Energy conservation terms for the restricted ventilation mode. (a) $\operatorname{HRR}\left(\dot{Q}_{f i r e}\right)$ generated by the burners for the fire spread modes. (b) $\dot{Q}_{\text {loss }}$ normalised by $\dot{Q}_{f i r e}$ for each fire spread mode. Comparing the normalised heat loss term ( $\left.Q_{\text {uss }}\right)$ established here for the travelling fire experiment to $\dot{Q}_{\text {loss }}$ obtained by Maluk et al. [12] for the same experiment shows similar heat losses using both methods. Similar trends are noted for the other fire spread modes for the experiments with restricted ventilation. Fig. $5 \mathrm{~b}$ shows a convergence of the heat loss term for the three fire spread modes, ranging around $45 \%$ to $55 \%$ of the total heat supplied by the burners. Using the calculation approach described in this study, or by Maluk et al. [12], the total heat losses do not match the heat release rate irrespective of the fire spread mode. It is believed that the disparity in the energy balance is attributed to a breakdown in the assumptions used to calculate the convective heat losses caused by the leakage of flow through the shutter roller doors used to restrict the ventilation. This is discussed further in Section 4.3. Average hot layer temperatures range from $300{ }^{\circ} \mathrm{C}$ to $380^{\circ} \mathrm{C}$, inflow velocities from $0.8 \mathrm{~m} \cdot \mathrm{s}^{-1}$ to $1 \mathrm{~m} . \mathrm{s}^{-1}$, outflow velocities from $2.2 \mathrm{~m} \cdot \mathrm{s}^{-1}$ to $2.6 \mathrm{~m} \cdot \mathrm{s}^{-1}$. 
The breakdown of the constituent heat loss pathways is shown in Fig. 5a. The error bars show the sensitivity of the convective, radiation and solid-phase loss components to the bounds of the thermal interface height $\left(H_{l}\right)$, effective flame temperature $\left(T_{F}\right)$, and the convective heat transfer coefficient $\left(h_{c}\right)$, respectively. The bounds for each parameter are determined experimentally over a time-averaged period, in the same manner as described by Gupta et al. [13].

Fig. 6a shows that the majority of the heat generated by the fire is lost through the enthalpy of the outflow irrespective of the fire spread mode. For the restricted ventilation mode, the thermal interface is fairly stable across the three openings; therefore, the error bars are not large. The exception to this is for the travelling fire spread mode $\left(V / V_{b o} \approx 1\right)$, where sharp differences in the thermal interface height local and remote from the fire are noted; therefore, the distribution in the convective heat losses is high. Radiation losses through the three openings are low $(<3 \%)$. Solid-phase losses are higher, with $9 \%$ to $11 \%$ of the HRR transferred to the boundary elements. These losses are far lower than those calculated by Harmathy [15] for compartments with similar inverse opening factors. The breakdown of solid-phase losses to the boundary elements in Fig. $6 \mathrm{~b}$ shows once again that most of the solid-phase heat losses are to the ceiling and back wall.
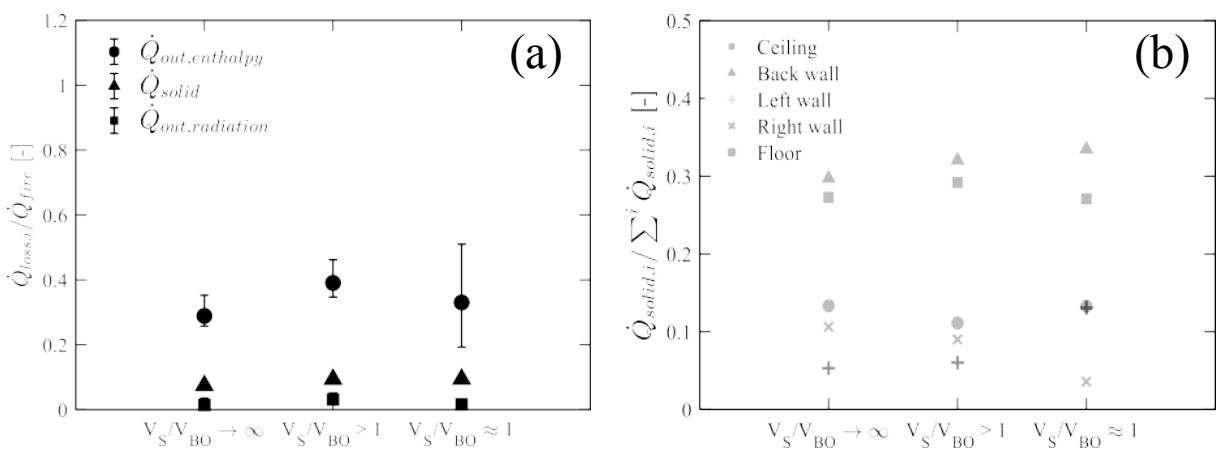

Fig. 6. Distribution of energy for the restricted ventilation mode. (a) Breakdown of the heat lost outside of the control volume to convection, radiation, and conduction. (b) Breakdown of the conduction losses to the various boundary elements in the compartment.

\subsection{Imbalances in energy conservation}

The repeatability of maintaining the experimental energy balance for the experiments with unrestricted openings $\left(\phi^{\prime} \approx 4 m^{-0.5}\right)$ highlights the robustness of the calculation approach of the total heat loss. Nevertheless, the experiments with restricted ventilation $\left(\phi^{\prime} \approx 23 \mathrm{~m}^{-0.5}\right)$ show that only $44 \%$ to $55 \%$ of the input HRR can be calculated using the proposed methodology. The HRR was calculated on the basis that the heat of combustion is ideal and that the base of the burner is well-ventilated. This assumption was deemed acceptable as external flaming was not observed [7], and flaming appears, for the most part, to be local to the burners. Thus, it is believed that well-ventilated conditions are obtained close to the burners. This observation is confirmed through analysis of the species concentrations of $\mathrm{O}_{2}, \mathrm{CO}_{2}$ and $\mathrm{CO}$ near the ceiling [7] as shown in Fig. 7. The oxygen concentrations in the experiments with restricted ventilation are slightly lower (by $0.5 \%$ to $2 \%$ compared to the unrestricted ventilation mode), highlighting a descending smoke layer as more oxygen is displaced from the ceiling. 
Temporal changes in the oxygen concentrations closely follow the evolution of the HRR for each ventilation mode and fire spread mode (refer to Fig. 3a and Fig. 5a). Due to the similar trends between oxygen and HRR, the amount of ventilation appears to have little effect on the availability of oxygen. The $\mathrm{CO} / \mathrm{CO}_{2}$ ratio is used to estimate the efficiency of the combustion. [19]. In both ventilation modes, this ratio is low and implies a close to ideal heat of combustion.
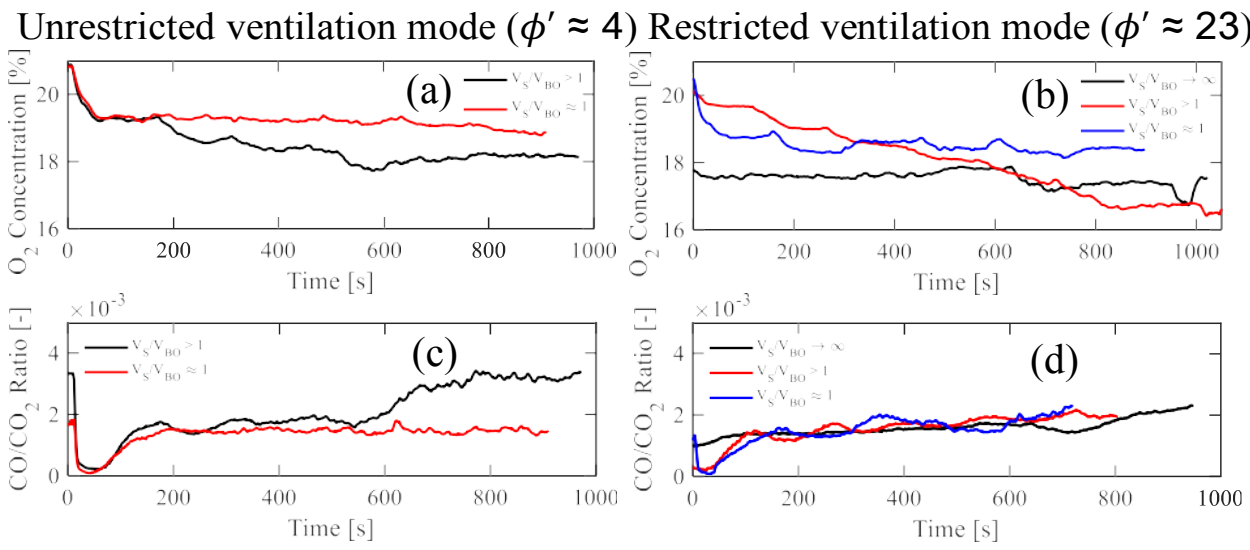

Fig. 7. Gas analysis of each fire spread mode. (a) $\mathrm{O}_{2}$ concentration for the unrestricted ventilation mode. (b) $\mathrm{O}_{2}$ concentration for the restricted ventilation mode. (c) $\mathrm{CO} / \mathrm{CO}_{2}$ ratio for the unrestricted ventilation mode. (d) $\mathrm{CO} / \mathrm{CO}_{2}$ ratio for the restricted ventilation mode.

The calculation of the convective losses assumes similarity of the neutral plane and thermal interface, which is valid for the well-ventilated experiments $\left(\phi^{\prime} \approx 4 \mathrm{~m}^{-0.5}\right)$ [13]. If the flow inside the compartment is hydrostatically-driven [15], the pressure build-up in the compartment displaces the neutral plane from the thermal interface. Therefore, the assumptions to calculate the convective heat losses for the restricted ventilation mode $\left(\phi^{\prime} \approx 23 m^{-0.5}\right)$ may not be valid.

It is believed that the poor estimation of the neutral plane height does not solely explain the significant disparity in the energy balance. Given the similarity in the calculation of $\dot{Q}_{\text {loss }}$ using the approach described in this study and by Maluk et al. [12], and on observations of the experiments, it is believed that there was significant leakage of flows through the shutters used to close the individual openings [7]. The enthalpy of this leakage was not captured with any sensors. Modelling the leakages as a hydrostatic horizontal vent [19] reveals enthalpy losses at approximately $30 \%$ to $40 \%$ of the total input HRR and may offer an explanation to the consistent errors in the energy balance assessment. Other potential causes for this imbalance such as less efficient combustion or external flaming were discarded as oxygen concentrations at the ceiling of the compartment were higher than $16 \%$ for experiments with restricted ventilation.

\section{Numerical characterisation of ventilation modes}

The gas analysis and observations of the experiments indicate low soot volume fractions, indicating that radiation from the smoke layer may not be the dominant heat transfer mode controlling the thermal boundary condition, thus convective heating to the structure must be considered. It is clear from the energy distribution analysis that changes in the ventilation induce shifts in the flow behaviour. This has distinct implications regarding the mechanisms of heat transfer to the boundaries. Quantification of the convective heat transfer requires the characterisation of the flow fields within the compartment, however this cannot be achieved experimentally since no flow sensors were placed within the compartment. 
To this purpose, a CFD model of the experiments is formulated using the Fire Dynamics Simulator version 6.7 .0 [20] with a $0.1 \times 0.1 \times 0.1 \mathrm{~m}$ mesh, totalling to $1,028,500$ cells to characterise the flow fields for the two ventilation bounds qualitatively. Only the fully-developed fire spread modes $\left(\bigvee / V_{B} \rightarrow \infty\right)$ are simulated, as they have the highest $\mathrm{HRR}$, and the two opening factors correspond to the classical definition of a ventilation-controlled fire and fuelcontrolled fire given by Thomas [2]. These two regimes represent the limiting cases of flow behaviour for fully-developed compartment fires (hydrostatic and momentum-driven respectively) [1]. The model is used to explore the flow behaviour at the two ventilation bounds, and quantify a characteristic velocity to define a convective heat transfer coefficient to calculate the thermal boundary conditions.

The compartment geometry, opening factor, the material composition of the walls (for the solidphase heat transfer model) and positioning of the burners are identical to the experimental setup [7]. Furthermore, the fuel and simulation parameters are identical to the model developed by Gupta et al. [13], with a validation study of the temperature fields (for the high ventilation experiment) performed at the same mesh size. The only change to the model is the variation in ventilation (i.e. closing the shutters and adjusting the input HRR). The input HRR mirrors those shown for the fully-developed fire spread mode for both ventilation modes in Fig. 3a and Fig. 5a.
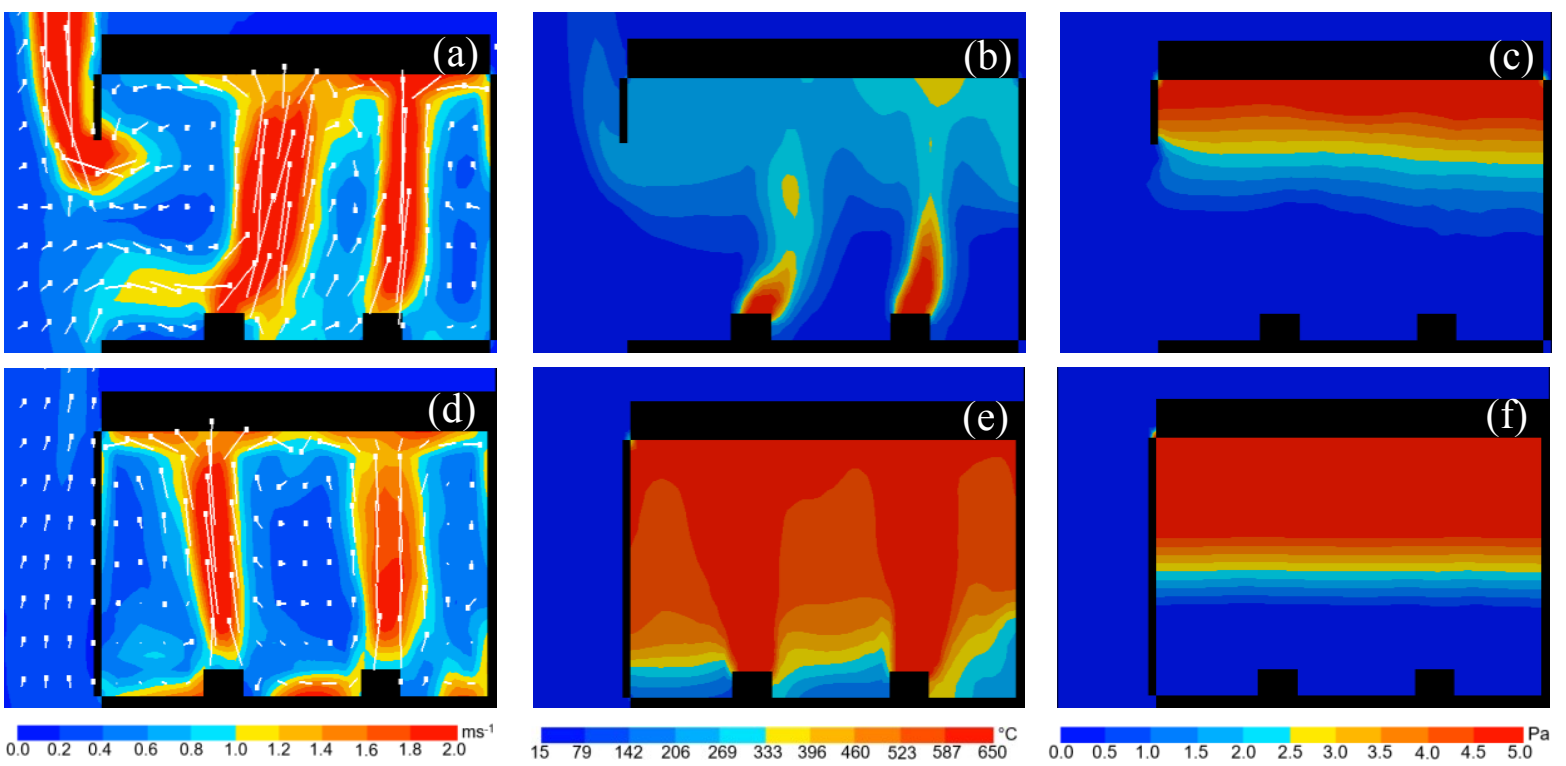

Fig. 8. Time-averaged contours of the velocities, temperatures, and pressures (from left to right) over the centreline of the burners near the centre of the compartment for $(a-c)$ unrestricted ventilation mode, and $(\mathrm{d}-\mathrm{f})$ restricted ventilation mode.

The contours of the velocities, temperatures, and pressures presented in Fig. 8 of the fullydeveloped fire experiments shows that the opening factor can have a considerable influence on the flow and thermal fields, even at large length scales. Qualitative observations of the unrestricted ventilation simulation show very high velocities within the plume, and at the ceiling jet, with the highest flows localised towards the rear wall. Outside of the accelerations local to the plume, both vertical and horizontal velocity gradients are strong. While not shown in these contours, spatially velocities along the ceiling are high, ranging from $1.5 \mathrm{~ms}^{-1}$ to $2.25 \mathrm{~ms}^{-1}$. Gasphase temperatures are low, with average hot layer temperatures ranging from $195^{\circ} \mathrm{C}$ to $245^{\circ} \mathrm{C}$, 
showing strong spatial distributions in temperatures within the compartments. While pressures are generally low, the high-pressure zone does not exceed the soffit height, indicating that gases are evacuated as fast as cold air is entrained into the flames.

Where ventilation is restricted, the results of the simulation also shows high velocities local to the plume and ceiling. The velocities along the ceiling tend to be more evenly distributed, with no concentration along the back wall. Outside of the accelerations local to the plume, momentum transport is limited, with the hot gases being transported laterally to the openings (not shown in the contour). Average hot layer temperatures are generally higher at approximately $500^{\circ} \mathrm{C}$, with a deeper and more uniform hot gas layer. The pressure fields indicate a build-up of a hot gas layer or a smoke layer well beyond the soffit height at the openings; however, the flow fields cannot be described as a well-stirred reactor, with partial mixing obtained.

Based on these descriptions, it is apparent that the flow fields in the compartment with unrestricted openings are controlled by the temperature gradient of the fire and the compartment. Therefore, the flow velocities along the boundaries are controlled by the characteristics of the plume and the resulting ceiling jet. When the openings are restricted, it is believed that the flow fields are controlled by a combination of hydrostatic flows in the hot layer, and the momentumdriven flows induced by the plume. Flow velocities along the ceiling are lower, and the high flows are concentrated to the point of impingement on the ceiling. Therefore, the flows and by extension, the convective heat transfer coefficients change as a function of the ventilation modes.

\section{Spatial heating analysis}

The compartment fire framework demarcates the different ventilation extremes by means of the different fire regimes to quantify a uniform thermal load to the structure. The results from this study and by those of Hidalgo et al. [7] and Maluk et al. [12] demonstrates the non-uniformity of heating in these experiments, especially in the transient fire spread modes. Assessment of the thermal load resulting from changes in ventilation must take into account the spatial heat distributions [3]. Given the insulating nature of the boundary elements, using the ratios of heat lost to the boundaries as the benchmark for severity can be misleading. Instead, the total incident heat flux onto the boundary elements $\left(q_{e}^{\prime \prime}\right)[15]$ is used to study the ventilation effects on the thermal environment. The high quantity of gas-phase temperature and irradiation measurements at or near the boundaries are exploited to analyse the total heat flux as a function of space and time. The total incident heat flux combines the irradiation and convective heat flux terms:

$$
q_{e}^{\prime \prime}=q^{\prime \prime}{ }_{\text {inc, } r a d}+h_{c}\left(\underset{g}{T}-T_{0}\right)
$$

where the reference temperature, $T_{0}$, is the ambient temperature instead of the element's surface temperature. This approach is similar to Law and O'Brien [21] and allows separating the incident heat flux from the net heat flux terms such that the boundary condition can be evaluated without consideration of the heat diffusion into the element. For analysis purposes, the total incident heat flux is non-dimensionalized using the heat release rate per unit floor area (HRRPUA):

$$
q^{*}=q_{e} / Q \text { fire }
$$

The irradiation term is solved using data from the TSCs, and the convective heat flux is evaluated using data from gas-phase thermocouples close to the TSCs. In order to determine the convective heat transfer coefficient for each ventilation mode, an average characteristic velocity 
$\left(v_{c}\right)$ is defined for both ventilation modes using the numerical models developed in Section 5. Spatial variations of flows along the ceiling are also considered. The convective heat transfer coefficient is evaluated using Eq. 5. For the unrestricted ventilation mode $\left(\phi^{\prime} \approx 4 m^{-0.5}\right)$, $v_{c}$ and $h_{c}$ are $2.25 \mathrm{~m} \cdot \mathrm{s}^{-1}$ and $12 \mathrm{~W} \cdot \mathrm{m}^{-2} \cdot \mathrm{K}^{-1}$, respectively, while for the restricted ventilation mode $\left(\phi^{\prime} \approx\right.$ $\left.23 \mathrm{~m}^{-0.5}\right)^{-} v_{c}$ and $h_{c}$ are $1 \mathrm{~m} \cdot \mathrm{s}^{-1}$ and $6 \mathrm{~W} \cdot \mathrm{m}^{-2} \cdot \mathrm{K}^{-1}$, respectively.

Unrestricted ventilation mode $\left(\phi^{\prime} \approx 4\right)$
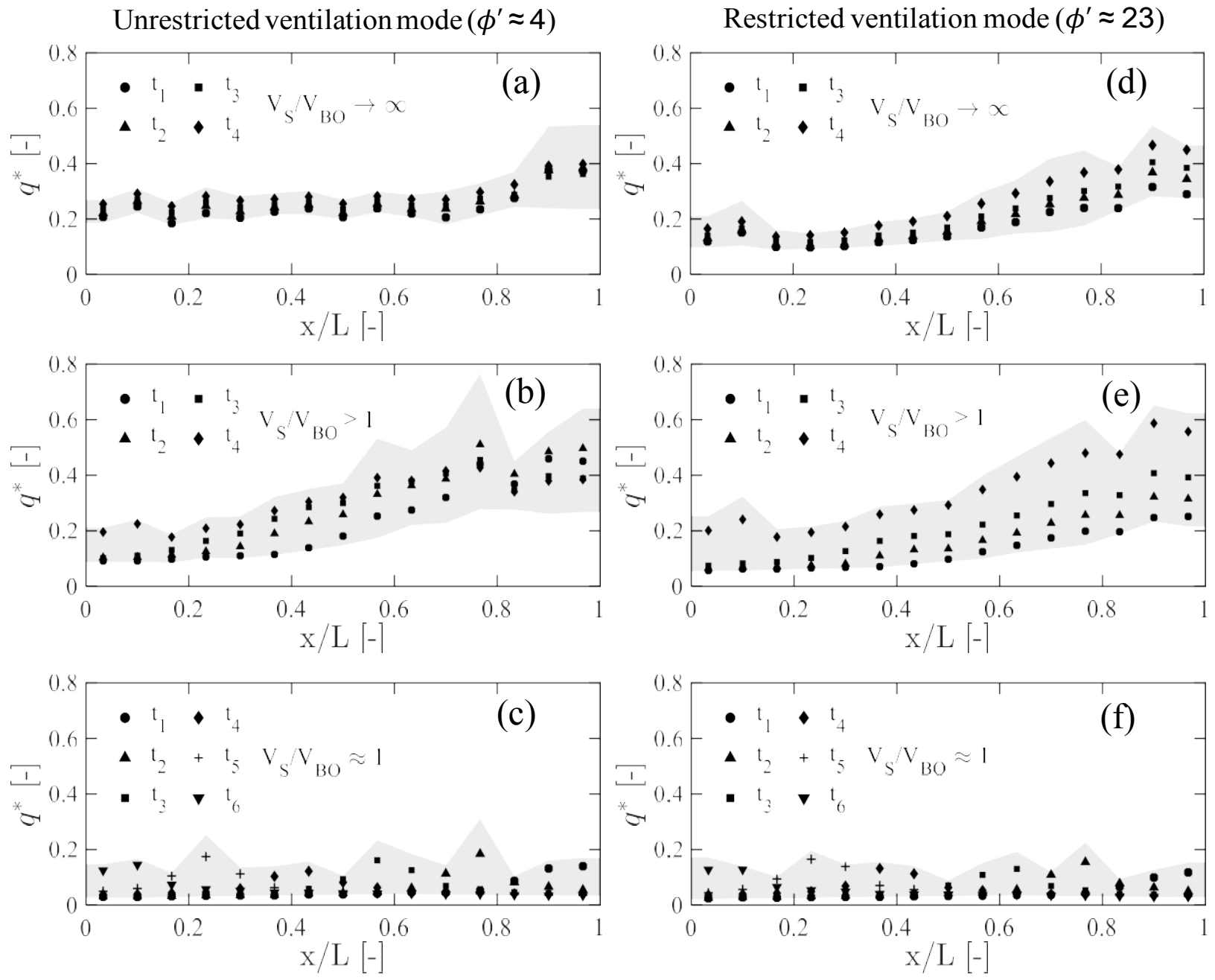

384

385

386

387

388

389

390

391

392

393

394

395

Fig. 9. Dimensionless spatial and temporal heating analysis of the ceiling. (a - c) fully-developed, growing and travelling fire spread modes (from top to bottom) for the unrestricted ventilation mode, and ( $\mathrm{d}$ - f) fully-developed, growing and travelling fire spread modes (from top to bottom) for the restricted ventilation mode.

The spatial heating analysis for each fire spread mode experiment under the two ventilation modes is shown in Fig. 9 for the ceiling. The spatial coordinate (shown on the $\mathrm{x}$-axis) is the length of the compartment that is presented as dimensionless. The markers on each figure indicate the temporal evolution of heating, with different time steps presented based on the steady-state periods of the HRR evolution of each experiment. These times represent the different stages of the fire progression and are time-averaged over one hundred seconds. The shaded region shows the maximum and minimum local heat variations at each length coordinate, measured along the compartment depth (i.e. from the back wall to the opening) over the entire 
period of each experiment. Detailed analysis of the discussion of the results is presented in Section 7.2. Nevertheless, it is important to highlight that these results demonstrate large spatial heating distributions dependent on the fire spread mode and that heating to the structure is generally higher in cases where ventilation is open and gas-phase temperatures are lower.

\section{Discussion}

\subsection{Comparison of ventilation effects on energy balance}

Considering that imbalances in energy conservation for the restricted ventilation experiments are the result of poor quantification of the convective heat losses, it is clear that majority of the heat generated by the combustion is lost through the enthalpy of the outflow. These results correspond to small-scale experiments with similar opening factors by Majdalani et al. [4]. The assumption of negligible radiation losses through the openings by Harmathy [15] for compartments with large inverse opening factors is shown to be valid for the experiments with restricted openings.

The solid-phase losses are low under both ventilation modes, with $9 \%$ to $11 \%$ and $6 \%$ to $8 \%$ of the input energy lost for the open and restricted ventilation modes. These losses represent a lower bound due to the low thermal inertia of the boundary materials [7]. Heating times of the boundaries are short, and quasi-steady conditions in the solid-phase are achieved, resulting in a decay in the net heat flux to the solid. In particular, the ceiling lining is high-density stone wool $\left(180 \mathrm{~kg} \cdot \mathrm{m}^{-3}\right)$, with a very low thermal conductivity $\left(0.036 \mathrm{~W} \cdot \mathrm{m}^{-2} \cdot \mathrm{K}^{-1}\right)$ as opposed to the walls; which consists of aerated concrete, with a higher density $\left(500 \mathrm{~kg} \cdot \mathrm{m}^{-3}\right)$ and thermal conductivity $\left(0.15 \mathrm{~W} \cdot \mathrm{m}^{-2} \cdot \mathrm{K}^{-1}\right)$. Due to the high incident heat fluxes and surface areas, the ceiling and back wall lose similar ratios of heat.

It is worth noting that the HRR relative to the size of the enclosure is not large; particularly for the fully-developed or growing fire spread modes. Soot yields for propane are lower than other hydrocarbons or cellulosic fuels, and in combination with the low HRR, soot volume fractions and the gas-phase temperatures are generally low. Majdalani et al. [4] shows that restricting the ventilation in combination with a higher HRR produces higher soot volume fractions, and thermal uniformity in the compartment is obtained. Under these conditions, solid-phase losses rise, and convective and radiative losses through the openings are minimized. Thus, the energy distribution shifts towards the ventilation-controlled fire described by Harmathy [15].

\subsection{Effects of ventilation on the spatial heat distribution}

Comparisons of the ventilation effects on the spatial heating show that equivalent levels of heating to the structure occur where openings are left unrestricted. This result is despite lower gas-phase temperatures and incident radiant heat fluxes, though flow velocities at the ceiling are significantly higher than the experiments with restricted openings. This trend is reflected across all three fire spread modes. In the absence of smoke layer formation, the convective heat transfer coefficient is much larger, and the lower gas-phase temperatures in the plume and ceiling jet can still deliver more heat to the structure. The transient fire spread modes under both ventilation modes impose significant spatial heat distributions along the ceiling. Under these cases, a single mean gas-phase temperature [2] or incident heat flux [15] does not serve as a robust indicator of thermal load. The heat delivered to the ceiling is relatively transient when the openings are restricted, likely as the smoke layer continues to descend, and the temperature in the layer rises 
due to the heat feedback loop. On the other hand, steady-state heat conditions are achieved faster when the openings are unrestricted as the smoke layer is not able to descend past the soffit. It is important to note that for the transient spread mode experiments, the HRRPUA is not preserved due to limitations in the propane supply of the burners and thus varies. The HRRPUA of the fully-developed fire mode experiments was $28 \mathrm{~kW} / \mathrm{m}^{2}$, the spreading fire mode ranges from 28 to $32 \mathrm{~kW} / \mathrm{m}^{2}$, and travelling fire mode is $70 \mathrm{~kW} / \mathrm{m}^{2}$ (as only two burners are operating at once).

Observations of the fully-developed fire mode $\left(V_{S} / V_{B O} \rightarrow \infty\right)$ [12] shows non-uniform propane supply to all the burners in the compartment. Flame heights to the right-hand side of the compartment $(x / L>0.8)$ are higher; therefore, heating is significantly larger in one side, causing large horizontal temperature gradients. Horizontal heat distributions stabilise away from the fire origin towards the left-hand side of the compartment $(\mathrm{x} / \mathrm{L}<0.6)$ shown in Fig. 9a and Fig. 9b.

Under both ventilation modes, the most severe heating conditions are observed for the growing mode $\left(\mathrm{V} / V_{b 0}>1\right)$, and spatially, heating is concentrated at the origin point of the fire spread $(\mathrm{x} / \mathrm{L}>0.6)$ shown in Fig. 9c and Fig. 9d. Spatial heating distributions are significant as the smoke layer forms locally at the fire origin, heating the boundaries local to the fire. Re-radiation effects of the walls and floor to the ceiling are also expected to induce a temperature rise locally. Furthermore, the short characteristic heating time of the boundaries due to the low thermal inertias exacerbate the temperature rise in the hot layer. Due to the low soot volume fractions, irradiation to the ceiling in the case of restricted openings is not the sole heat transfer mechanism. Therefore, heating is controlled by the gas-phase temperatures and the speed of the flows along the ceiling in addition to radiation from the smoke layer.

According to travelling fire theory [22], the thermal fields in a compartment fire can be demarcated into a near-field local to the fire, and a far-field remote from the fire. Demarcation of the two zones is based on the flame thickness over the fuel bed. Examination of Fig. 9e and Fig. 9f shows a clear separation of the near-field heating and far-field heating at different times along the compartment. The heated length is a function of the timescales of the fire movement, and farfield heating decays very quickly after this region is passed. Near-field heating conditions are similar to the lower pre-heated regions in the fire growth $\left(\zeta / V_{b o}>1\right)$ and fully-developed $\left(\bigvee / V_{b o} \rightarrow \infty\right)$ fire spread experiments under both ventilation modes. It is apparent that the local heating duration has a major influence on the spatial heating distributions in the compartment. The ventilation mode is shown to also influence the levels of near-field heating; with higher levels of heating and higher spatial heat distributions in the case where the openings are left open. Interestingly, far-field heating to the ceiling is equivalent under both ventilation modes, indicating low gas-phase temperatures and irradiation remote from the fire. It is worth noting that in spite of a higher HRRPUA for the travelling fire spread modes, the heat delivered to the ceiling local to the fire is similar to the other fire spread modes away from the region of preheating $(\mathrm{x} / \mathrm{L}<0.6)$. This observation confirms that the near-field heating is defined by the local gas-phase temperatures, irradiation from the flames and the ceiling flows.

\section{Conclusions}

It is well known that ventilation is a critical parameter that governs the intensity and duration of a fully-developed fire within ventilation-restricted compartments, studied within the context of the current compartment fire framework. As the built environment tends towards large open-plan spaces $\left(>150 \mathrm{~m}^{3}\right)$, there is a need to characterise the fire behaviour inside well-ventilated compartments. Recent experiments in large-scale compartments have challenged the assumption 
of temperature homogeneity and demonstrated that such spaces could not be described using the current framework. Further, it has been shown that spatial temperature distributions may induce complex thermally driven forces into contemporary structural systems.

Recent demonstrator experiments on natural fuel beds in large-scale, fuel-controlled, open-plan type compartments have identified three fire spread modes, corresponding to a fully-developed fire, a growing fire, and a travelling fire. These fire spread modes were controlled during fire testing by using computer-controlled propane gas burners. The fire behaviour resulting from each fire spread modes demonstrates the characteristics of behaviours that are spatially and temporally variant based on the timescales associated with (1) the fire spread at the front of the burning fuel, (2) the burnout front of burnout fuel front, (3) and the ventilation mode.

Analysis of the energy distribution and numerical model reveals a departure in the characteristic fire dynamics of the compartment fire framework that is based on hydrostatic flows controlling the thermal loads within the compartment. Flows within the compartment are controlled by the momentum of the fire plume, with the ventilation acting as the regulator to the plume-induced flows. The assertion that higher gas-phase temperatures and irradiation to the boundaries resulting from restricted ventilation present a more onerous thermal loading scenario is challenged. The analysis shows that compartments with large openings and limited smoke layer accumulation will induce higher momentum-driven flows, and therefore a high convective heat transfer coefficient. Thermal loading to the compartment boundaries, driven by convective heating can deliver equivalent levels of severity, despite lower gas-phase temperatures and irradiation. Thus, proper quantification of the thermal boundary condition resulting from a specified fire scenario must also consider the ventilation characteristics and the resultant fireinduced flows within the compartment.

\section{Acknowledgements}

This work formed part of the EPSRC funded Real Fires for the Safe Design of Tall Buildings project (Grant No. EP/J001937/1) at the University of Edinburgh. The authors acknowledge Benjamin Linnan, Andy Wong, Tam Do and Pravi Patel for past work analysing these experiments, which has been beneficial to this study. The data and code that enable the analysis can be obtained from https://doi.org/10.7488/ds/2477 under a Creative Commons License.

\section{References}

[1] J.L. Torero, A.H. Majdalani, A.E. Cecilia, A. Cowlard, Revisiting the compartment fire, Fire Saf. Sci. 11 (2014) 28-45. doi:10.3801/IAFSS.FSS.11-28.

[2] P.H. Thomas, A.J.M. Heselden, Fully Developed Fires in Single Compartments, (1972).

[3] A. Cowlard, A. Bittern, C. Abecassis-Empis, J.L. Torero, Some Considerations for the Fire Safe Design of Tall Buildings, Int. J. High-Rise Build. 2 (2013) 63-77.

[4] A.H. Majdalani, J.E. Cadena, A. Cowlard, F. Munoz, J.. Torero, Experimental characterisation of two fully-developed enclosure fire regimes, Fire Saf. J. 79 (2016) 10 19. doi:10.1016/j.firesaf.2015.11.001.

[5] R.G. Gann, A. Hamins, K. McGrattan, H.E. Nelson, T.J. Ohlemiller, K.R. Prasad, W.M. Pitts, Reconstruction of the Fires and Thermal Environment in World Trade Center Buildings 1, 2, and 7, Fire Technol. 49 (2013) 679-707. doi:10.1007/s10694-012-0288-3.

[6] T. Lennon, D. Moore, The natural fire safety concept - Full-scale tests at Cardington, Fire 
Saf. J. 38 (2003) 623-643. doi:10.1016/S0379-7112(03)00028-6.

525

526

527

528

529

530

531

532

533

534

535

536

537

538

539

540

541

542

543

544

545

546

547

548

549

550

551

552

553

554

555

556

557

558

559

560

561

562

563

564

[7] J.P. Hidalgo, A. Cowlard, C. Abecassis-Empis, C. Maluk, A.H. Majdalani, S. Kahrmann, R. Hilditch, M. Krajcovic, J.L. Torero, An experimental study of full-scale open floor plan enclosure fires, Fire Saf. J. 89 (2017) 22-40. doi:10.1016/j.firesaf.2017.02.002.

[8] J.P. Hidalgo, T. Goode, V. Gupta, A. Cowlard, C. Abecassis-Empis, J. Maclean, A.I. Bartlett, C. Maluk, J.M. Montalvá, A.F. Osorio, J.L. Torero, The Malveira fire test: Fullscale demonstration of fire modes in open-plan compartments, Fire Saf. J. 108 (2019) 102827. doi:10.1016/j.firesaf.2019.102827.

[9] P.H. Thomas, A.J. Heselden, M. Law, Fully-developed Compartment Fires: Two Kinds of Behaviour, 1967.

[10] J.P. Hidalgo, C. Maluk, A. Cowlard, C. Abecassis-Empis, M. Krajcovic, J.L. Torero, A Thin Skin Calorimeter (TSC) for quantifying irradiation during large-scale fire testing, Int. J. Therm. Sci. 112 (2017) 383-394. doi:10.1016/j.ijthermalsci.2016.10.013.

[11] B.J. McCaffrey, G. Heskestad, A robust bidirectional low-velocity probe for flame and fire application, Combust. Flame. 26 (1976) 125-127. doi:10.1016/0010-2180(76)900626.

[12] C. Maluk, B. Linnan, A. Wong, J.P. Hidalgo, J.L. Torero, C. Abecassis-Empis, A. Cowlard, Energy distribution analysis in full-scale open floor plan enclosure fires, Fire Saf. J. (2017) 1-10. doi:10.1016/j.firesaf.2017.04.004.

[13] V. Gupta, C. Maluk, J.L. Torero, J.P. Hidalgo, Analysis of Convective Heat Losses in a Full-scale Compartment Fire Experiment, in: Proc. 9th Int. Semin. Fire Explos. Hazards, 2019: pp. 490-501. doi:10.18720/spbpu/2/k19-53.

[14] A.H. Majdalani, Compartment Fire Analysis for Contemporary Architecture, (2014).

[15] T.Z. Harmathy, A new look at compartment fires, part II, Fire Technol. 8 (1972) 326-351. doi:10.1007/BF02590537.

[16] S. Welch, A. Jowsey, S. Deeny, R. Morgan, J.L. Torero, BRE large compartment fire tests-Characterising post-flashover fires for model validation, Fire Saf. J. 42 (2007) 548567. doi:10.1016/j.firesaf.2007.04.002.

[17] G. Heskestad, Virtual origins of fire plumes, Fire Saf. J. 5 (1983) 109-114. doi:10.1016/0379-7112(83)90003-6.

[18] K.S. Mudan, Thermal radiation hazards from hydrocarbon pool fires, Prog. Energy Combust. Sci. 10 (1984) 59-80. doi:10.1016/0360-1285(84)90119-9.

[19] D. Drysdale, An Introduction to Fire Dynamics, 3rd ed., Wiley, 2011. doi:10.1016/03797112(86)90046-9.

[20] K. McGrattan, S. Hostikka, R. McDermott, J. Floyd, M. Vanella, FDS user guide, (2019). doi:10.6028/NIST.SP.1019.

[21] M. Law, T. O'Brien, Fire Safety of Bare External Structural Steel, The Steel Construction Institute, 1989.

[22] J. Stern-Gottfried, G. Rein, Travelling fires for structural design-Part II: Design methodology, Fire Saf. J. 54 (2012) 96-112. doi:10.1016/j.firesaf.2012.06.011. 


\section{Figure captions}

566 Fig. 1. (a) Isometric sketch of the experimental compartment geometry, with internal dimensions.

567 (b) Plan view of the burners and opening shutters. (c) Shutters system covering the openings..... 2

568 Fig. 2. Cumulative view factor distribution of the highlighted flames...................................5

569 Fig. 3 Energy conservation terms for the high ventilation regime (a) $H R R\left(Q_{\text {fire }}\right)$ generated by

570 the burners for three fire spread modes. (b) $Q_{\text {loss }}$ normalised by $Q_{\text {fire }}$ for each fire spread mode. 6

571 Fig. 4. Distribution of energy for the unrestricted ventilation mode. (a) Breakdown of the heat

572 lost outside of the control volume to convection, radiation, and conduction. (b) Breakdown of the

573 conduction losses to the various boundary elements in the compartment.

574 Fig. 5. Energy conservation terms for the restricted ventilation mode. (a) $H R R\left(Q_{\text {fire }}\right)$ generated

575 by the burners for three fire spread modes. (b) $Q_{\text {loss }}$ normalised by $Q_{\text {fire }}$ for each fire spread

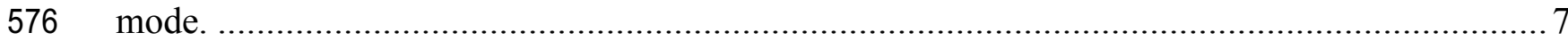

577 Fig. 6. Distribution of energy for the restricted ventilation mode. (a) Breakdown of the heat lost

578 outside of the control volume to convection, radiation, and conduction. (b) Breakdown of the

579 conduction losses to the various boundary elements in the compartment. ............................ 8

580 Fig. 7. Gas analysis of each fire spread mode. (a) $\mathrm{O}_{2}$ concentration for the unrestricted ventilation

581 mode. (b) $\mathrm{O}_{2}$ concentration for the restricted ventilation mode. (c) $\mathrm{CO} / \mathrm{CO}_{2}$ ratio for the

582 unrestricted ventilation mode. (d) $\mathrm{CO} / \mathrm{CO}_{2}$ ratio for the restricted ventilation mode.

583 Fig. 8. Time-averaged contours of the velocities, temperatures, and pressures (from left to right)

584 over the centerline of the burners near the centre of the compartment for (a-c) unrestricted

585 ventilation mode, and (d-f) restricted ventilation mode.

586 Fig. 9. Dimensionless spatial and temporal heating analysis of the ceiling. (a-c) fully-developed, 587 growing and travelling fire spread modes (from top to bottom) for the unrestricted ventilation

588 mode, and (d-f) fully-developed, growing and travelling fire spread modes (from top to bottom)

589 for the restricted ventilation mode 